\title{
Evidence of healing of partial-thickness rotator cuff tears following arthroscopic augmentation with a collagen implant: a 2-year MRI follow-up
}

\author{
Desmond John Bokor ${ }^{1}$ \\ David Sonnabend ${ }^{2}$ \\ Luke Deady ${ }^{3}$ \\ Ben Cass ${ }^{4}$ \\ Allan Young 4 \\ Craig Van Kampen ${ }^{5}$ \\ Steven Arnoczky 6 \\ 1 Department of Orthopaedic Surgery, Faculty of \\ Medicine and Health Sciences, Macquarie \\ University, Australia \\ 2 Department of Orthopaedic Surgery, Royal North \\ Shore Hospital, St Leonards, Australia \\ 3 Alfred Imaging \& Alfred Advanced Sports Imaging \\ Centre, Drummoyne, Australia \\ 4 Sydney Shoulder Specialists, St. Leonards, \\ Australia \\ 5 Rotation Medical, Inc, Plymouth, USA \\ 6 College of Veterinary Medicine Michigan State \\ University, East Lansing, USA
}

Corresponding author:

Desmond John Bokor

Department of Orthopaedic Surgery, Faculty of

Medicine and Health Sciences, Macquarie University

2 Technology Place

2109 Macquarie University, Australia

E-mail: desbok@iinet.net.au

\section{Summary}

Background: partial-thickness rotator cuff tears frequently enlarge due to increased local strain and often progress to full-thickness tears. Studies suggest the addition of new tendinous tissue to injured cuff tendons would significantly decrease peak strain, possibly protecting against tear progression. The aim of this study was to assess the ability of a highly-porous collagen implant to induce new tissue formation and limit tear progression when placed on the bursal surface of partialthickness cuff tears.

Methods: following arthroscopic subacromial decompression, the implant was attached to the bursal surface of the supraspinatus tendon in a prospective series of 13 consecutive patients with intermediate - (3-6 $\mathrm{mm})$ to high-grade $(>6 \mathrm{~mm})$ partial - thickness cuff tears ( 5 articular, 3 bursal,
5 intra-substance). Tendon thickness, defect size, and tendon quality were evaluated using magnetic resonance imaging (MRI) preoperatively and at $3,6,12$, and 24 months postoperatively. Clinical outcomes were assessed using the Constant and American Shoulder and Elbow Society scores at the same preoperative and follow-up times. All 13 patients completed all follow-up exams (mean length of follow-up 27.0 months, range 23.3-32.0); no patients were lost to follow-up.

Results: the implant induced significant new tissue formation in all patients by 3 months (mean increase in tendon thickness $2.2 \pm 0.26 \mathrm{~mm}$ ). This tissue matured over time and became radiologically indistinguishable from the underlying tendon. The partial-thickness cuff tears showed consistent filling of the defects, with complete healing in 7 patients at 12 months, and a progressive improvement in tendon quality in the remaining patients. No tear progression was observed by MRI in any of the patients at $\mathbf{2 4}$ months. All clinical scores improved significantly over time. At 24 months, 12 of 13 patients $(92 \%)$ had satisfactory or better results.

Conclusions: the results of this clinical study demonstrated the ability of a highly-porous collagen implant to induce new tendon-like tissue formation and create an environment conductive to the healing of partial-thickness cuff tears.

KEY WORDS: partial-thickness rotator cuff tear, tendon healing, collagen implant, MRI.

\section{Introduction}

Partial-thickness rotator cuff tears represent a significant challenge to the arthroscopic surgeon. Although the precise incidence of partial-thickness tears is unknown, cadaveric and clinical studies have demonstrated an increase in partial-thickness rotator cuff tears with age ${ }^{1-3}$. This suggests that the prevalence of partial-thickness cuff tears is likely to increase in the aging population ${ }^{4}$.

There is no consensus on a single algorithmic treatment approach to a patient with a symptomatic, partial-thickness rotator cuff tear ${ }^{4}$. The treatment of cuff tears involving less than $50 \%$ of the tendon thickness has ranged from non-operative activity modification and rehabilitation to tear debridement with or without subacromial decompression ${ }^{4}$. However, because par- 
tial-thickness rotator cuff tears have been shown to frequently enlarge over time and often progress to full-thickness tears ${ }^{5-10}$, more attention may need to be directed to the tendon itself.

While some studies suggest there is an absence of an active repair response at the site of the tendon injury ${ }^{11,12}$, other studies have demonstrated that partialthickness ${ }^{13}$ and small full-thickness ${ }^{14}$ cuff tears have an active cellular response and do possess some intrinsic healing ability. Although the biological potential for repair of partial-thickness cuff tears appears to exist, other factors such as age, subacromial impingement, degenerative changes, and increased shear stresses within the tendon may adversely affect this process $^{15}$.

Experimental studies have demonstrated that differential shear stress within the supraspinatus tendon can lead to partial-thickness tears ${ }^{16}$. Once present, these tears can significantly increase local intra-tendinous strain which is thought to contribute to further tissue degeneration, impaired healing, and tear propagation $^{16-20}$. A finite-element study has demonstrated that by increasing the thickness of the supraspinatus tendon by $2 \mathrm{~mm}$ on its bursal surface, peak intratendinous strain can be decreased by $47 \%$ in bursalsided, partial-thickness tears and by $40 \%$ in articularsided, partial-thickness tears ${ }^{21}$. The ability to decrease local tendon strain by the addition of new tissue may represent a novel approach to the treatment of partial-thickness rotator cuff injuries.

An experimental study in sheep has demonstrated the ability of a highly-porous, low modulus, reconstituted collagen implant to consistently increase the thickness of a rotator cuff tendon by inducing the formation of a well-integrated and mature tendon-like tissue ${ }^{22}$. In addition, a recent clinical study has demonstrated the ability of this collagen implant to increase the thickness of the supraspinatus tendon following augmentation of full-thickness, rotator cuff repairs ${ }^{23}$.

Therefore, the purpose of the current clinical study was to evaluate the effect of this implant placed arthroscopically on the bursal surface of the supraspinatus tendon in patients with partial-thickness tears. It was hypothesized that the implant would induce rapid tissue ingrowth and create an environment that would permit the functional maturation and alignment of new tendon-like tissue over the surface of the injured tendon as determined by sequential magnetic resonance imaging (MRI). It was also hypothesized that this new tissue would limit tear progression and prevent further degenerative changes within the tendon.

\section{Materials and methods}

This study was conducted in accord with international standards and meets the ethical standards of the Muscles, Ligaments, and Tendons Journal ${ }^{24}$. This trial was registered with the Australia New Zealand Clinical Trials Registry (Trial ID: ACTRN12611001082998).

\section{Patient enrollment}

Following Ethics Committee approval, patients with partial-thickness tears of the supraspinatus tendon were recruited for a study to determine the effect of a highly-porous collagen implant (Rotation Medical Inc., Plymouth, Minnesota), arthroscopically attached to the bursal surface of the tendon, on tissue induction, tendon quality and integrity, and clinical outcomes over a 24-month period. All patients signed informed consent.

Inclusion criteria included chronic shoulder pain lasting longer than 3 months (resistant to analgesics, anti-inflammatory medication, and physical therapy) and patient age 40-67 years old at surgery. Exclusion criteria included recent steroid use, insulin-dependent diabetes, heavy smoking, genetic collagen disease, chronic inflammatory disease, and index shoulders with previous cuff surgery. Patients with shoulder instability, grade 3 or greater chondromalacia, or grade 2 or greater fatty infiltration of the supraspinatus muscle were also excluded. The implant is contraindicated for patients with a known hypersensitivity to bovine collagen.

Thirteen consecutive patients with partial-thickness tears of the supraspinatus tendon, with the articularand bursal-sided tears confirmed at surgery, met the criteria and were enrolled in the study. No patients were excluded from the analysis.

\section{Collagen implant}

The reconstituted collagen scaffolds were made from highly-purified, type I collagen from bovine tendons using proprietary methods (Collagen Matrix, Inc., Oakland, New Jersey) ${ }^{22,23}$. The collagen fibers were processed to create a highly oriented and highly porous (85-90\% porosity) collagen scaffold with a DNA content of less than $50 \mathrm{ng} / \mathrm{mg}^{22,23}$. The scaffolds were freeze-dried after processing and rehydrated at the time of surgery 22,23 . The rehydrated scaffold dimensions were approximately $15 \mathrm{~mm}$ wide, $30 \mathrm{~mm}$ long, and $2 \mathrm{~mm}$ thick ${ }^{22,23}$.

\section{Surgical technique}

Surgery was performed under general anesthesia in either the lateral decubitus or beach chair position. Following arthroscopic assessment of the glenohumeral joint, a subacromial bursectomy and decompression were performed prior to placement of the implant. If indicated, the following procedures were also performed: biceps tenodesis or tenotomy, debridement of minor fraying of the labrum or cuff tendon, and/or release of the coracoacromial ligament.

The implant was arthroscopically placed on the bursal surface of the supraspinatus tendon using customdesigned instrumentation (Rotation Medical Inc., Plymouth, Minnesota). An implant size (20x25 or $25 \times 30$ $\mathrm{mm}$ ) was selected to cover almost the entire width of the supraspinatus tendon. The anterior edge of the implant was aligned with the anterior edge of the 
supraspinatus tendon, using previously placed markers as a guide. The lateral end of the implant was positioned to overlap onto bone approximately $5 \mathrm{~mm}$ beyond the lateral edge of the supraspinatus footprint. The implant, which is designed to absorb within 6 months, was affixed to the supraspinatus tendon medially, anteriorly, and posterior lyusing custom-designed PLA staples, which are designed to absorb in approximately 12 months, and to the bone laterally using custom-designed PEEK staples (Rotation Medical Inc., Plymouth, Minnesota). The implant was attached under slight tension to assure good contact with the underlying tendon (Fig. 1).

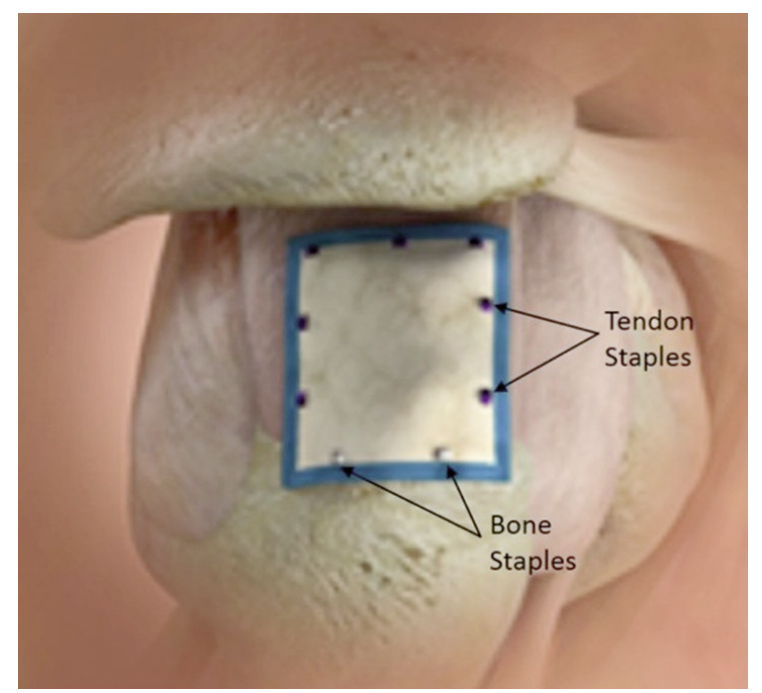

Figure 1. Schematic drawing of the implant in place over the supraspinatus tendon secured to cuff and bone with staples.

\section{Postoperative care}

The use of the implant did not require any significant changes to the postoperative protocol used for patients undergoing arthroscopic acromioplasty. Patients were instructed to discontinue the sling when comfortable (maximum of 1 week) and progress as tolerated from passive to active-assisted to active motion. Active motion was allowed with forward flexion limited to $100^{\circ}$ for the first 4 weeks. No resistance exercises were allowed for 6 weeks. After 6 weeks there were no restrictions on the use of the arm.

\section{MRI assessment}

Patients had MRIs preoperatively and at 3, 6, 12, and 24 months postoperatively. The scans were done at two institutions on 3 Tesla scanners using $2 \mathrm{~mm}$ slices, with proton density (PD) and T2 weighted scans, with and without fat saturation. All of the MR images were read by a single musculoskeletal radiologist who was blinded to the clinical outcomes. All of the measurements were made using the PD fat suppressed images.

In order to accurately measure the thickness of the supraspinatus tendon, the coronal scan was modified to a double-oblique angle that was aligned with the length of the supraspinatus tendon (coronal plane angled slightly anteriorly) and perpendicular to its thickness (oblique coronal plane tilted slightly anteriorly). Scans were also done in the sagittal and axial planes. The thickness measurements were made in the area of the tear from the coronal images just medial to the articular margin of the supraspinatus insertion (Fig. 2). For each patient, all of the follow-up measurements were made as close as possible to the location where the preoperative measurement was made.

MRI assessment of the size of the cuff defects was

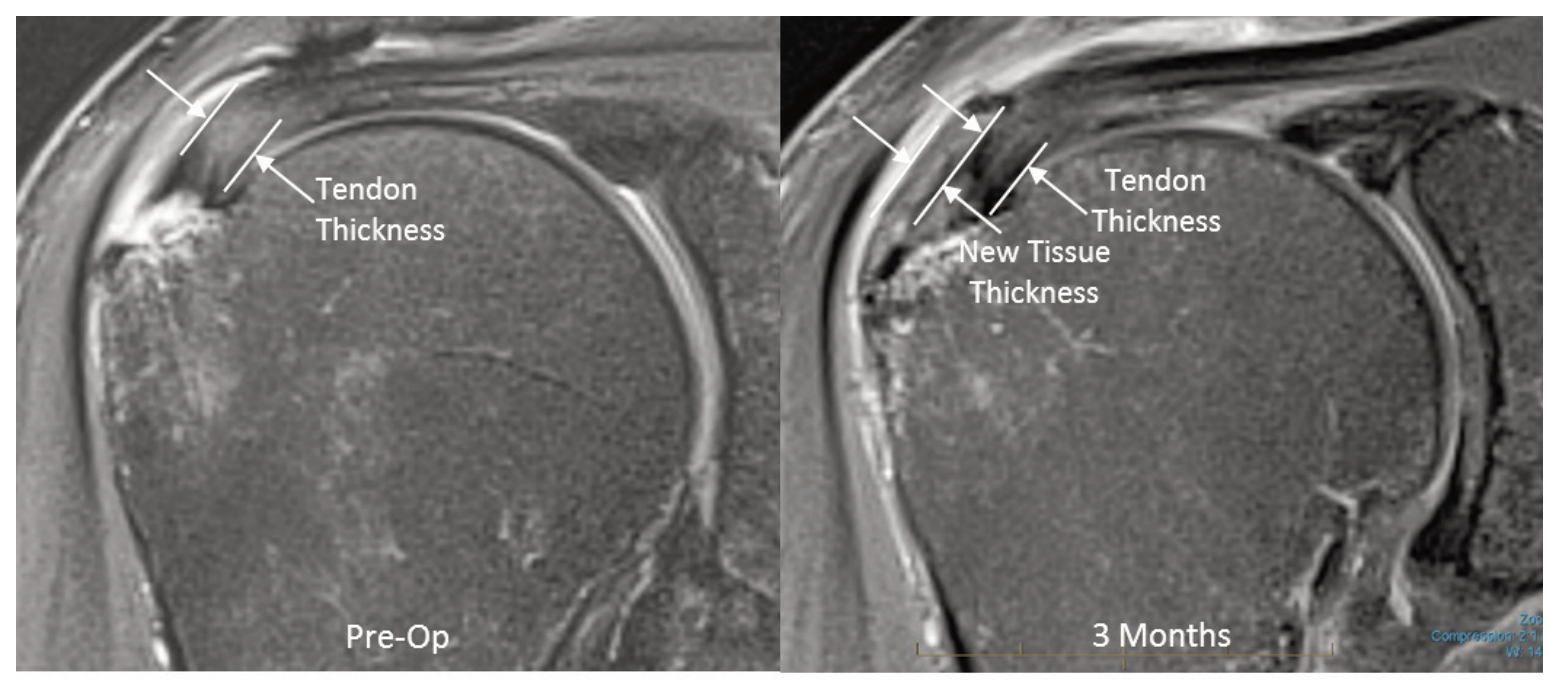

Figure 2. Preoperative and postoperative MRIs from same patient demonstrating thickness measurements. (PD Fat Suppressed Images). 
used to determine if the tears progressed, remained the same, or reduced in size. The tear size was estimated by analyzing the entire sequence of images from the coronal, sagittal, and axial scans. For each patient the longitudinal comparisons were made as reproducibly as possible.

\section{Clinical assessment}

Clinical assessments included the Constant-Murley shoulder score (not age or gender adjusted) and the American Shoulder and Elbow Society (ASES) shoulder scale, both administered preoperatively and at 3 , 6,12 , and 24 months postoperatively. These validated shoulder-specific assessments include both functional parameters and pain assessment.

\section{Statistical analysis}

Differences in tendon thickness over time were analyzed using a repeated measures ANOVA and changes in clinical scores were assessed using the Friedman two-way ANOVA for non-parametric data. Differences between individual time periods were evaluated using post-hoc analyses and statistical significance was considered at $p<0.05$.

\section{Results}

The 13 patients in this study had an average age of 53.8 years (range 42-67); 8 were male and 5 female, with 8 right and 5 left shoulders treated. At time of surgery, there were 6 intermediate-grade $(3-6 \mathrm{~mm})$ and 7 high-grade $(>6 \mathrm{~mm}$ ) tears; 5 were articular-sided ( 2 high-grade, 3 intermediate-grade), 3 were bursalsided ( 1 high-grade, 2 intermediate-grade), and 5 were intra-substance (4 high-grade, 1 intermediate-grade). The mean length of follow-up was 27.0 months (range 23.3-32.0). All 13 patients completed all of the followup exams; no patients were lost to follow-up.

\section{MRI assessment of tendon thickness}

Three months following surgery there was a significant $(p<0.0001)$ increase in new tissue induction over the bursal surface of the supraspinatus tendon, resulting in a mean increase in tendon thickness of $2.2 \pm$ $0.26 \mathrm{~mm}$ (SEM). Over the next 9 months the increase in tendon thickness remained stable and MRI assessment of the new tissue demonstrated a progressive maturation to more tendon-like signal (Fig. 3). At 12 months the new tissue was indistinguishable from the underlying tendon in 12 of 13 patients. While there

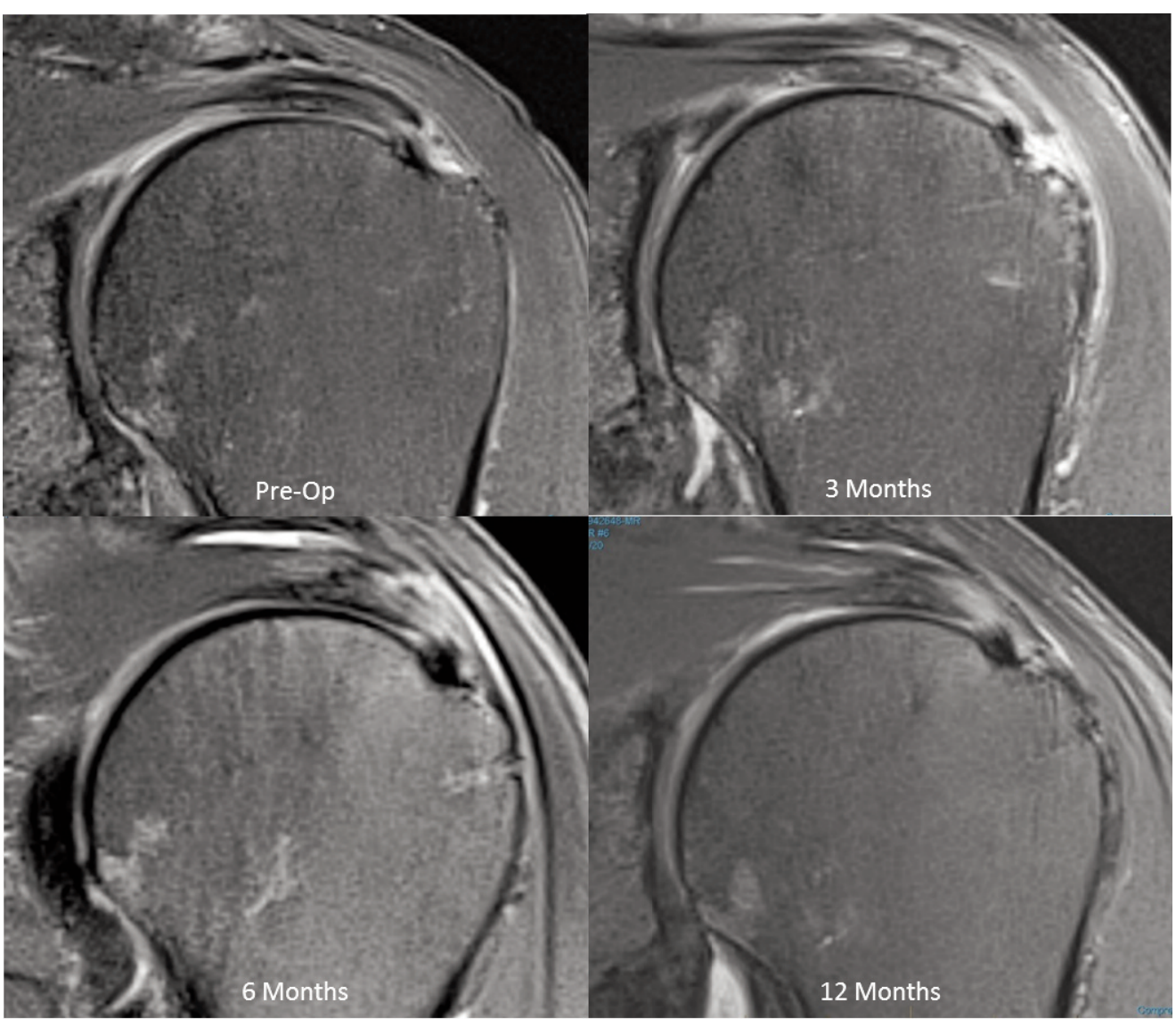

Figure 3. MRI sequence demonstrating the new tissue signal becoming indistinguishable from the underlying tendon at 12 months (PD Fat Suppressed Images). 


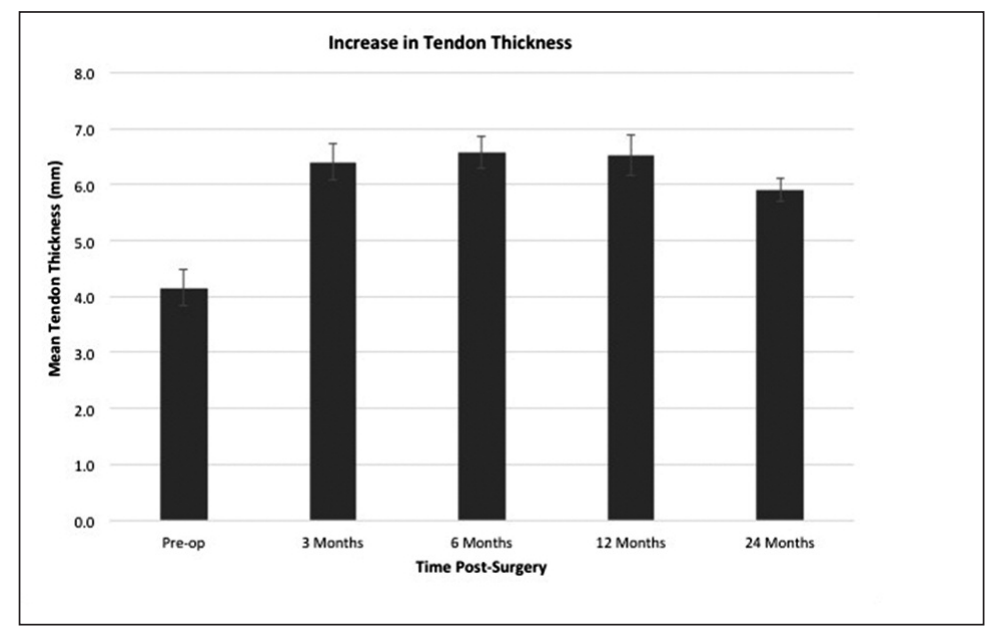

Figure 4. Mean tendon thickness over 24month period including standard error of the mean.

was a slight decrease $(p=0.003)$ in tendon thickness between 12 and 24 months, the tendons remained significantly $(p<0.0001)$ thicker than their preoperative measurements (Fig. 4).

\section{MRI assessment of defect size}

Comparison of the postoperative MRI tear size to the preoperative tear size was limited to 10 patients because the preoperative tear size in 3 patients could not be clearly identified by MRI (one bursal-sided, two articular-sided). In all 10 patients with measurable preoperative tear sizes, there was a progressive filling-in of the defects and by 12 months, 7 patients demonstrated complete disappearance of the tear (Fig. 5) and 3 patients demonstrated partial (>50\%) filling-in of their defects (Tab. 1). In these 3 patients MRI showed continued, albeit incomplete, healing of the defects at 24 months (Fig. 6).

All the other 3 patients, with preoperative tears not clearly identified by MRI, demonstrated progressive improvement in tendon quality over the 24-month period (Fig. 7). None of the 13 patients demonstrated MRI evidence of tear propagation or progressive tendon degeneration over the 24-month postoperative period.

\section{Clinical assessment}

Constant and ASES scores showed steady improvement throughout the 24-month follow-up period. There were significant improvements in overall Constant score $(p \leq 0.01)$, Constant pain score, $(p \leq$ $0.001)$ ASES total score $(p \leq 0.001)$, and ASES pain score $(p \leq 0.001)$.

At 24 months, 12/13 (92\%) of the patients had satisfactory or better results. The patient with the unsatisfactory result stated she had significant pain despite her Constant pain score improving from 15 preoperatively to 8 at 24 months. Her MRIs demonstrated excellent tissue induction and complete resolution of her intermediate-grade, bursal-sided tear.

\section{Complications}

One patient experienced excessive swelling of the shoulder during the arthroscopic procedure necessitating conversion to a mini-open approach. There were no postoperative infections and no adverse events associated with the device.

There were 3 patients that had issues believed to be unrelated to the device. One patient developed adhesive capsulitis, however, final follow-up showed resolution and improved clinical scores. One patient with biceps tendinitis spontaneously ruptured the long head and his pain resolved at 14 months. One patient experienced pain 12 months after surgery associated with significant bursitis, which settled following arthroscopic debridement. At time of arthroscopic debridement the high-grade, articular-sided cuff tear looked as if it had healed (Fig. 8). Cultures and histology from biopsies obtained during the clean-up procedure showed no evidence of infection and no unanticipated reaction associated with the implant or staples. While it is possible that the bursal reaction in this patient may have been elicited by the device, there was no conclusive histological evidence that confirmed the device to be the cause of the bursitis. A follow-up MRI, 6 months after arthroscopic debridement, showed a normal bursa, retention of the new induced tissue, and complete healing of the preoperative articular-sided, partial-thickness tear (Fig. 9).

\section{Discussion}

The concept that partial-thickness tears of the supraspinatus tendon could spontaneously heal was first proposed by Codman ${ }^{25}$. Although clinical studies have documented spontaneous healing in a limited number of partial-thickness cuff tears ${ }^{6,9}$ numerous other studies have shown that these partial-thickness lesions often enlarge and progress to full-thickness tears ${ }^{5-7,9,10,26-28}$. While the reasons for the impaired healing of partial-thickness tears are likely multi-fac- 


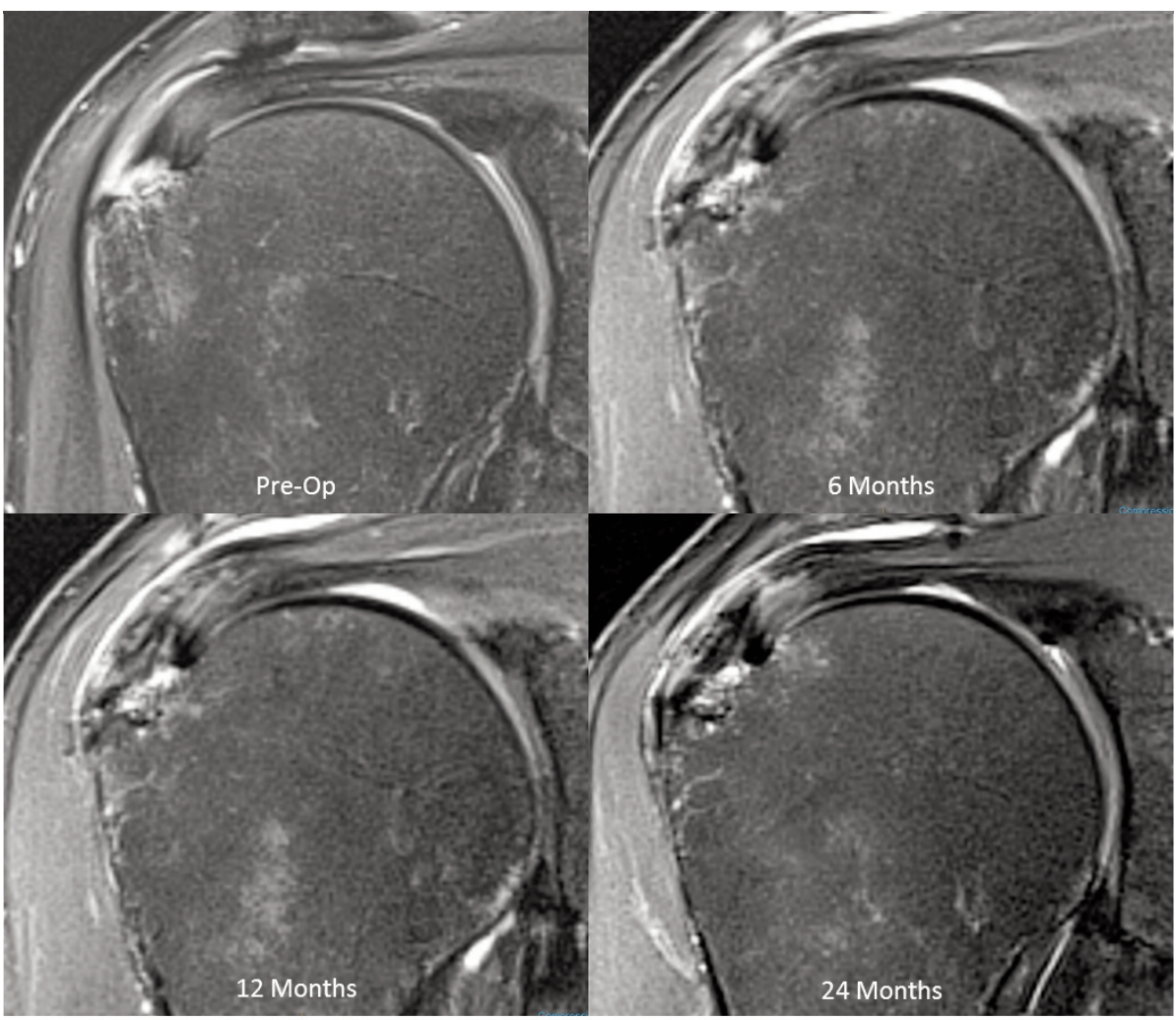

Figure 5. MRI sequence demonstrating healing of high-grade intra-substance tear over 24 months (PD Fat Suppressed Images).

Table 1. Sequential improvement and healing of cuff defects over 24-month period.

\begin{tabular}{|c|c|c|c|c|c|c|}
\hline \multicolumn{2}{|c|}{ Tear Location / Size } & \multicolumn{5}{|c|}{ Number of Patients $(n=10)$} \\
\hline & & Pre-Op & 3 Months & 6 Months & 12 Months & 24 Months \\
\hline \multirow{4}{*}{$\begin{array}{l}\text { Bursal } \\
(n=2)\end{array}$} & No Tear & 0 & 0 & 0 & 1 & 1 \\
\hline & Low-Grade & 0 & 1 & 1 & 1 & 1 \\
\hline & Intermediate-Grade & 1 & 0 & 1 & 0 & 0 \\
\hline & High-Grade & 1 & 1 & 0 & 0 & 0 \\
\hline \multirow{4}{*}{$\begin{array}{l}\text { Articular } \\
(n=3)\end{array}$} & No Tear & 0 & 0 & 1 & 2 & 2 \\
\hline & Low-Grade & 0 & 1 & 2 & 1 & 1 \\
\hline & Intermediate-Grade & 2 & 2 & 0 & 0 & 0 \\
\hline & High-Grade & 1 & 0 & 0 & 0 & 0 \\
\hline \multirow{4}{*}{$\begin{array}{l}\text { Intra-Substance } \\
(n=5)\end{array}$} & No Tear & 0 & 0 & 3 & 4 & 4 \\
\hline & Low-Grade & 0 & 3 & 2 & 1 & 1 \\
\hline & Intermediate-Grade & 1 & 2 & 0 & 0 & 0 \\
\hline & High-Grade & 4 & 0 & 0 & 0 & 0 \\
\hline
\end{tabular}




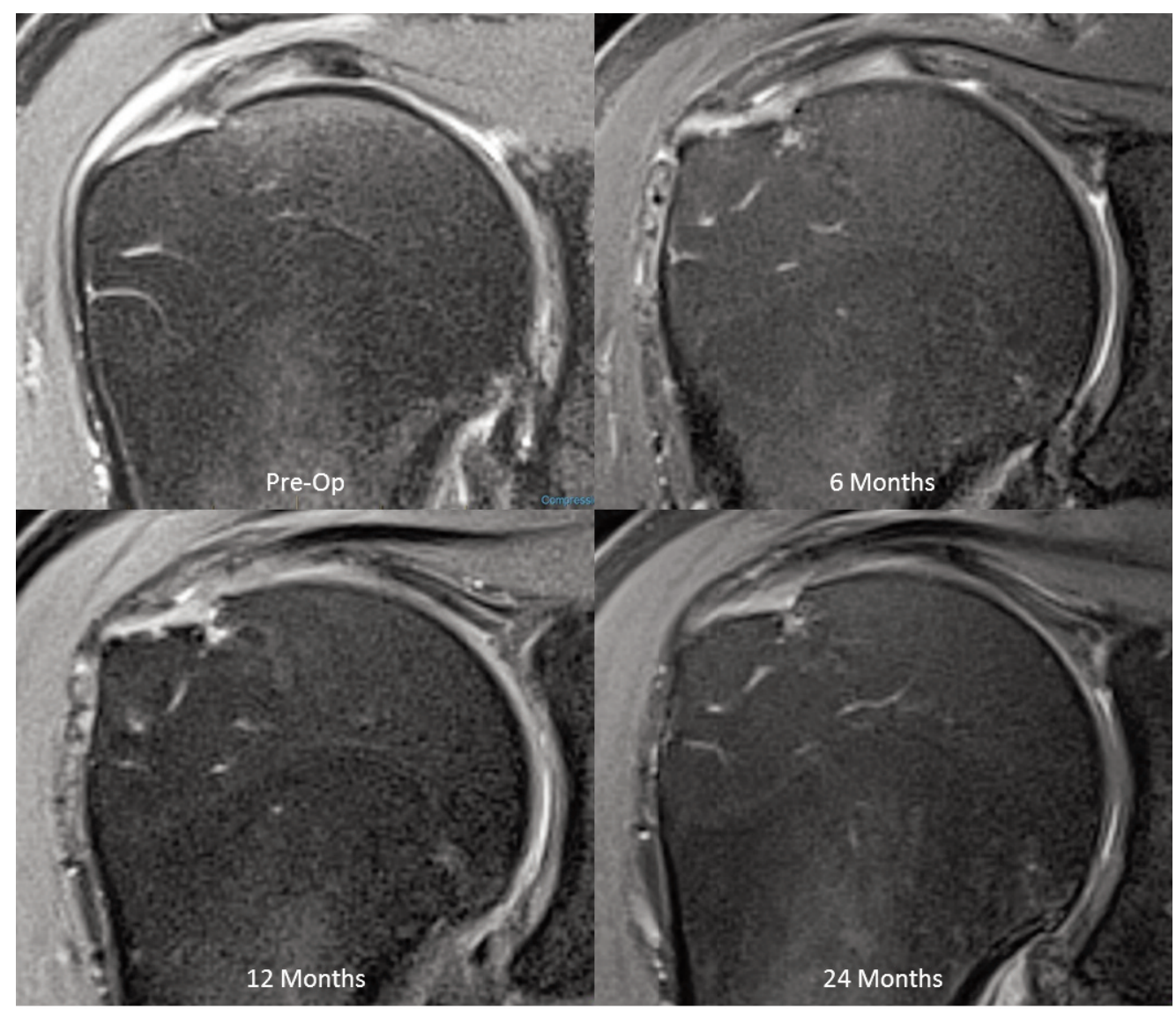

Figure 6. MRI demonstrating improvement in tendon signal in one of the patients that showed incomplete healing of the tear over the 24-month follow-up (PD Fat Suppressed Images).

torial, the increase in shear forces within the tendon following injury is thought to play a major role in disease progression ${ }^{16-20}$. Indeed, studies have demonstrated the inhibitory effect of shear forces on wound healing in other collagenous tissues ${ }^{29,30}$. The addition of $2 \mathrm{~mm}$ of new, tendon-like tissue over the bursal surface of the supraspinatus tendon has been proposed as a way to reduce the stress within the injured tendon and improve the healing environment for partial-thickness cuff tears ${ }^{21,22}$.

The results of the current study demonstrate the ability of partial-thickness rotator cuff tears (bursal, articular, and intra-substance) to decrease in size, and in most cases disappear. The healing of these partialthickness defects is associated with the induction of new, tendon-like tissue following arthroscopic placement of a highly-porous, collagen implant on the bursal surface of the injured cuff tendon. MRI evaluation revealed the generation of new tissue over the bursal surface of the supraspinatus tendon in all patients by 3 months, which persisted over the 24-month evaluation period. During this time, the new tissue demonstrated functional organization, maturation, and remodeling as evidenced by the MRI signal of this new tissue becoming indistinguishable from the native tendon. The slight decrease in tendon thickness between 12 and 24 months likely reflects the continued functional remodeling of the induced tissue. An association between decreasing tissue stresses and decreasing area of repair tissue in the remodeling of healing tendons has been previously demonstrated ${ }^{31}$. The rapid induction of new tissue, which matured and remodeled into dense, regularly-oriented connective tissue, mirrored the histological progression of the implant-induced tissue demonstrated in a preclinical sheep study 22 .

The increase in new tissue and tendon thickness observed in the current study was accompanied by a progressive improvement in the MRI signal quality of the underlying tendon in all patients. Seven of the patients demonstrated complete fill-in of their defects by 12 months. While the precise histologic nature of the tissue that filled these defects is unknown, MRI assessment suggests maturation toward a tendon-like tissue in these defects over time. Previous studies have suggested that rotator cuff tears can produce an active local cellular response and possess some intrinsic healing ability ${ }^{13,14}$. However, previous clinical experience has suggested that spontaneous healing of partial-thickness tears is unlikely due to several factors, including excessive shear stresses within the injured tendon ${ }^{15}$. The induction of new tissue demonstrated in the current study may have decreased these stresses, thus optimizing the mechanical envi- 


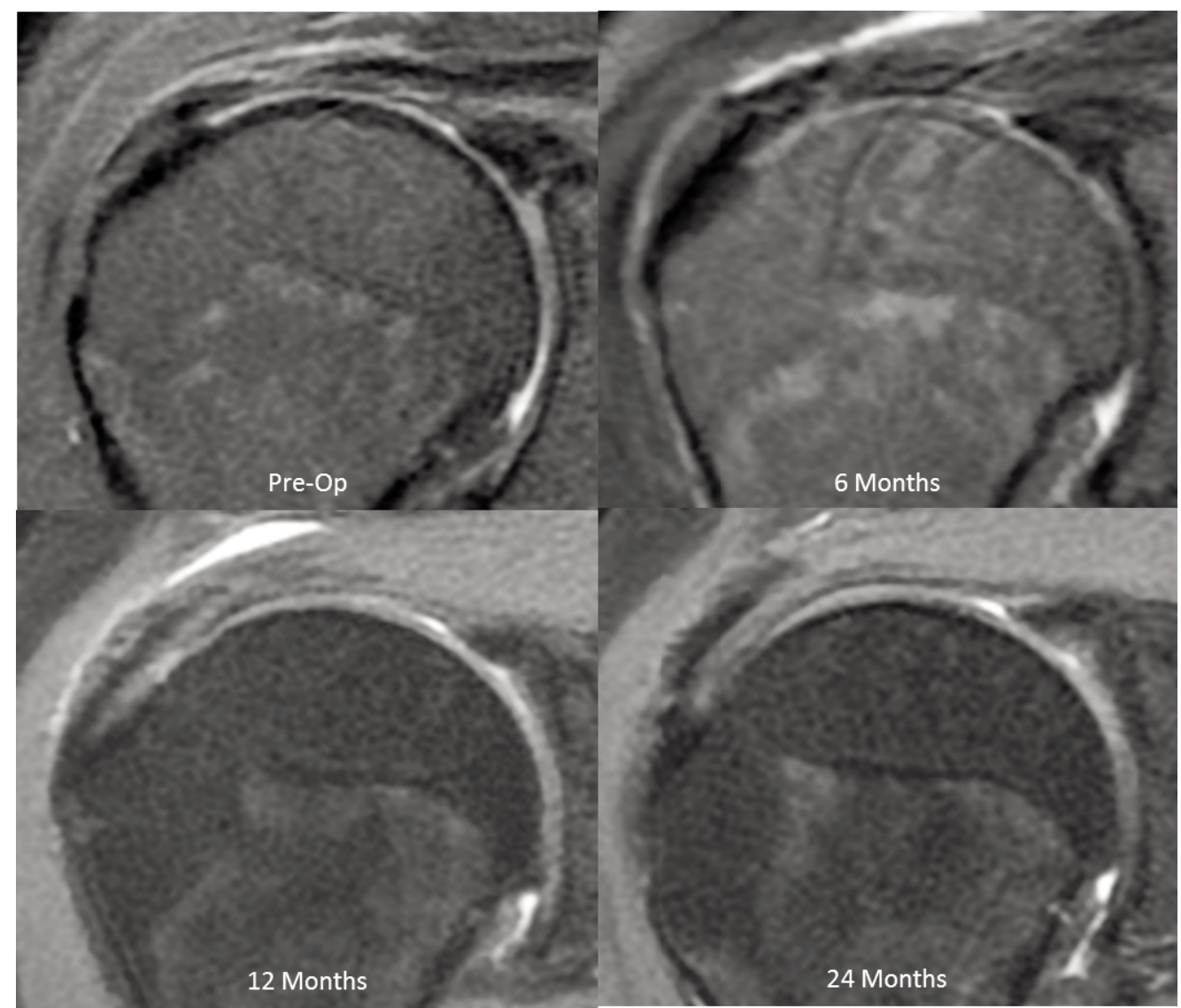

Figure 7. Preoperative MRI showing tendinosis which at surgery demonstrated an intermediate-gradebursal-sided tear. Postoperative MRIs show thickening of the tendon and improvement of the quality of the internal signal within the supraspinatus tendon (PD Fat Suppressed Images).
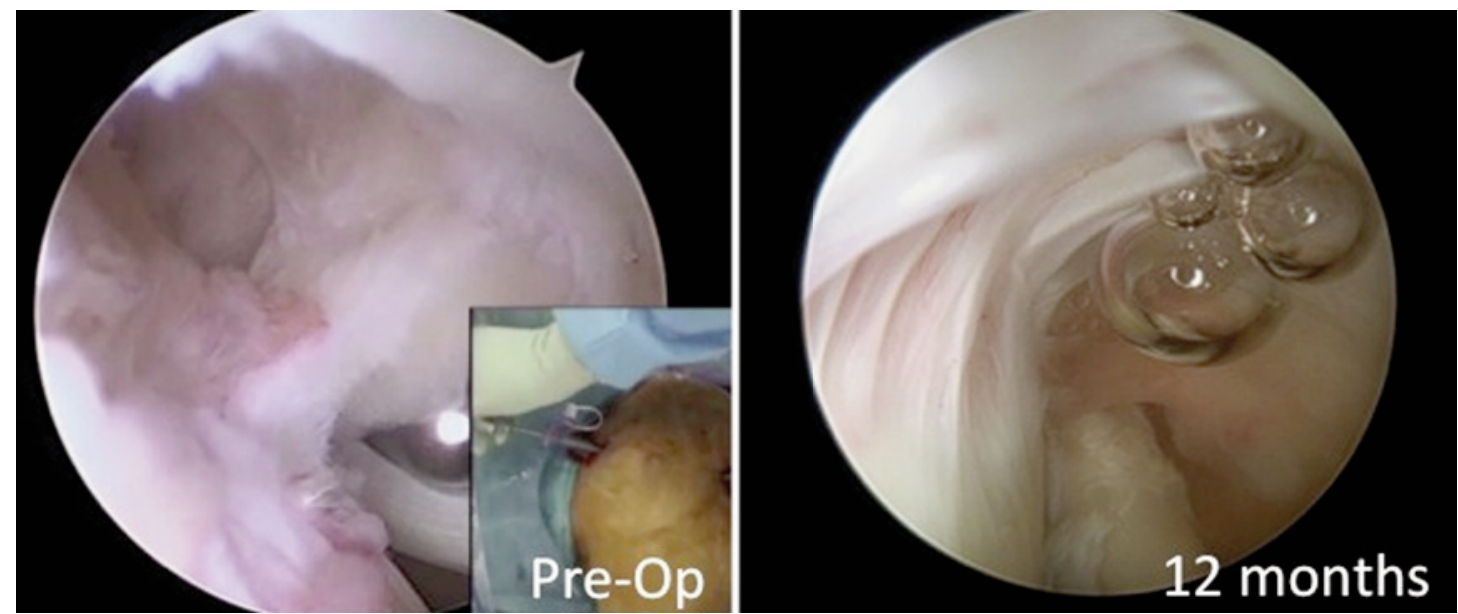

Figure 8. Preoperative and 12-month postoperative arthroscopic appearance of high-grade articular-sided tear demonstrating healing.

ronment and allowing normal healing to take place. Three patients in this study did not demonstrate complete resolution of their partial-thickness tears, however, there was progressive fill-in of the defects over 24 months. The reason for the incomplete healing in these patients is unclear and may be related to age, two of these patients being older (62 and 67 years), or any of a number of other biologic factors that may hinder tendon healing ${ }^{15}$. A histologic study has theorized that the presence of a synovial lining found in 


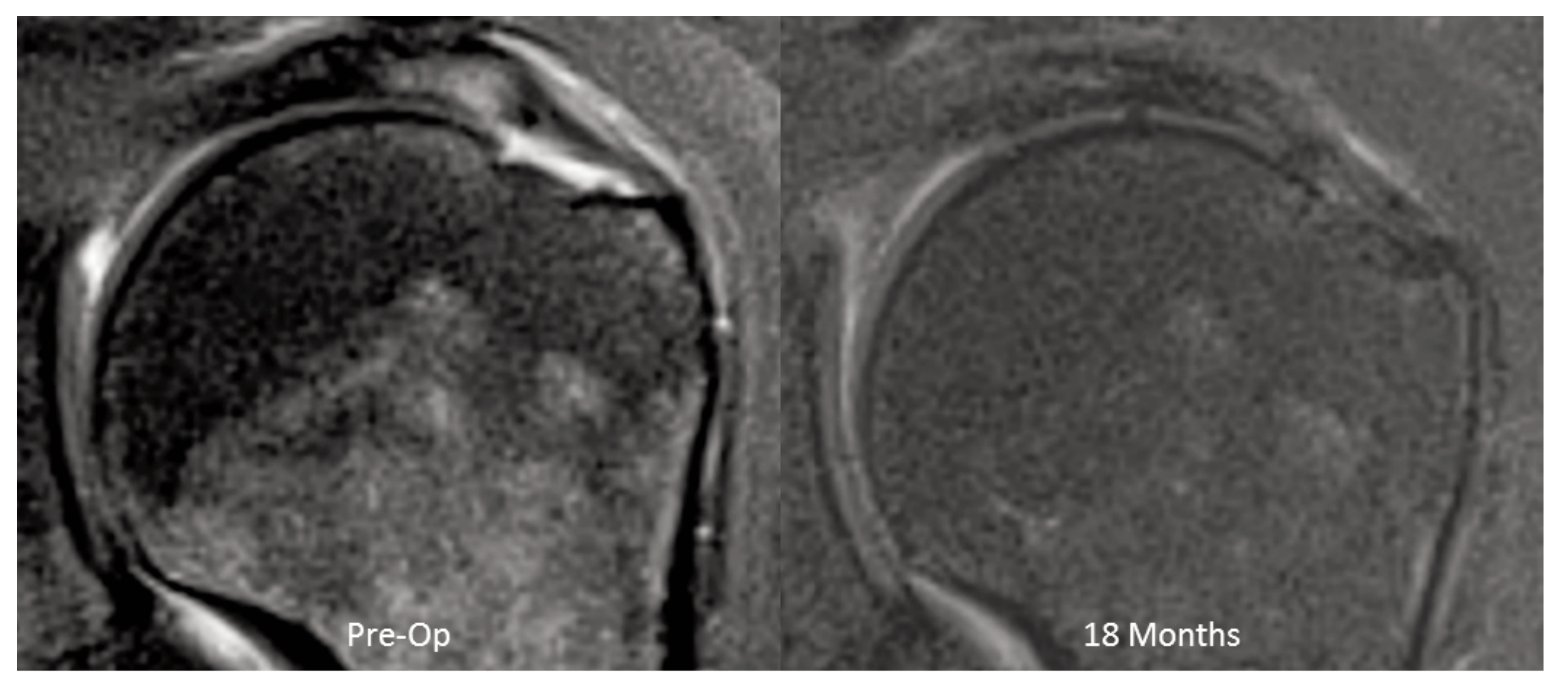

Figure 9. MRIs of the patient in Figure 8, preoperative and 6 months following arthroscopic debridement (18 months after initial implant insertion), showing complete healing of the tear and normal bursa (PD Fat Suppressed Images).

laminated extensions of cuff tears may inhibit repair ${ }^{32}$. The ability to identify and address specific risk factors for impaired healing of rotator cuff tears will be a key factor in improving outcomes.

The Constant and ASES scores significantly improved over time in all patients. Previous studies have reported satisfactory results ranging from 45 to $88 \%$ following treatment of partial-thickness rotator cuff tears with arthroscopic acromioplasty alone 27,28, 33,34 . Tear size 28 , patient age ${ }^{28}$, and other shoulder pathology 33 have been shown to affect these outcomes. Based on previous studies, the $92 \%$ satisfactory results in the current study suggests some benefit from the induction of new tissue (and subsequent improvement and healing of the defects) over acromioplasty alone. Additional studies are needed to increase patient numbers and confirm this theory.

As with most clinical investigation, there are potential limitations of the current study which must be placed in context. These include the lack of a prospective control cohort and the limited number of subjects. While several studies have shown similar improvements in clinical scores following arthroscopic subacromial decompression alone $27,33,34$, none have demonstrated the increase in tendon thickness, the universal absence of tear progression, and the improvement in tendon quality and healing seen in the current study. A study of 40 patients with partial-thickness cuff lesions followed for a mean of 13.5 months, showed $80 \%$ of the lesions to have enlarged or progressed to full-thickness lesions ${ }^{9}$. Another study has demonstrated the progression of tear size in partialthickness lesions in patients followed for greater than 18 months $^{6}$. Finally, a recent study has documented a $44 \%$ incidence of enlargement of partial-thickness rotator cuff tears ${ }^{35}$. Therefore, using peer-reviewed data as historic controls, it could be expected to see at least some evidence of tear progression in this cohort of partial-thickness lesions over the two year duration of this study. In the current study, the absence of any MRI evidence of tear progression, coupled with the consistent improvement in MRI appearance and overall reduction in defectsize at 24 months, suggests a beneficial effect of the implant-induced tissue. Of course, longer-term evaluation will be necessary to assess the durability of these results.

In conclusion, the results of this clinical study demonstrate the ability of partial-thickness tears of the supraspinatus tendon to heal following arthroscopic placement of a highly-porous, tissue inductive collagen implant. This is consistent with previous finite element analysis predictions that the induction of $2 \mathrm{~mm}$ of new tissue over the bursal surface of the supraspinatus tendon would significantly decrease intratendinous strain caused by partial-thickness tears 21 and thus improve the healing environment for bursal, articular, and intra-substance lesions. The ability to heal partial-thickness rotator cuff defects, and thus prevent tear propagation and progressive tendon degeneration, represents a novel interventional treatment paradigm for these lesions.

\section{Acknowledgements}

The Authors thank Jenny Burke, Eileen Cole, Bruno Giuffre, Sue Goldrick, Charles Ho, Jeff Mclntosh, and Jil Woodfor for their advice and assistance.

\section{Conflict of interests}

The Authors declare that they have no conflict of interests regarding the publication of this paper.

\section{References}

1. Fukuda H. Partial-thickness rotator cuff tears: a modern view on Codman's classic. J Shoulder Elbow Surg. 2000;9(2):163168.

Muscles, Ligaments and Tendons Journal 2016;6 (1):16-25 
2. Milgrom C, Schaffler M, Gilbert S, van Holsbeeck M. Rotator cuff changes in asymptomatic adults. The effect of age, hand dominance and gender. J Bone Joint Surg Br. 1995;77(2):296298.

3. Sher JS, Uribe JW, Posada A, Murphy BJ, Zlatkin MB. Abnormal findings on magnetic resonance images of asymptomatic shoulders. J Bone Joint Surg Am. 1995;77(1):10-15.

4. Finnan RP, Crosby LA. Partial-thickness rotator cuff tears. J Shoulder Elbow Surg. 2010;19(4):609-616.

5. Mall NA, Kim HM, Keener JD, et al. Symptomatic progression of asymptomatic rotator cuff tears: a prospective study of clinical and sonographic variables. J Bone Joint Surg Am. 2010;92 (16):2623-2633

6. Maman E, Harris C, White L, Tomlinson G, Shashank M, Boynton E. Outcome of nonoperative treatment of symptomatic rotator cuff tears monitored by magnetic resonance imaging. J Bone Joint Surg Am. 2009;91(8):1898-1906.

7. Ozbaydar MU, Bekmezci T, Tonbul M, Yurdoglu C. The results of arthroscopic repair in partial rotator cuff tears. Acta Orthop Tramatol Turc. 2006;40(1):49-55.

8. Strauss EJ, Salata MJ, Kercher J, et al. The arthroscopic management of partial-thickness rotator cuff tears: a systematic review of the literature. Arthroscopy. 2011;27(4):568-580.

9. Yamanaka K, Matsumoto T. The joint side tear of the rotator cuff. A follow up study by arthrography. Clin Orthop Relat Res. 1994;(304):68-73.

10. Yamaguchi K, Tetro AM, Blam O, Evanoff BA, Teefey SA, Middleton WD. Natural history of asymptomatic rotator cuff tears: a longitudinal analysis of asymptomatic tears detected sonographically. J Shoulder and Elbow Surg. 2001;10(3):199-203.

11. Fukuda H, Hamada K, Nakajima T, Yamada N, Tomonaga A, Goto M. Partial-thickness tears of the rotator cuff. A clinicopathological review based on 66 surgically verified cases. Int Orthop. 1996;20(4):257-265

12. Wolff AB, Sethi $P$, Sutton KM, Covey AS, Magit DP, Medvecky M. Partial-thickness rotator cuff tears. J Am Acad Orthop Surg. 2006;14(13):715-725

13. Hamada K, Tomonaga A, Gotoh M, Yamakawa H, Fukuda H. Intrinsic healing capacity and tearing process of torn supraspinatus tendons: in situ hybridization study of alpha 1(I) procollagen mRNA. J Orthop Res. 1997;15(1):24-32.

14. Matthews TJ, Hand GC, Rees JL, Athanasou NA, Carr AJ. Pathology of the torn rotator cuff tendon. Reduction in potential for repair as tear size increases. J Bone Joint Surg $\mathrm{Br}$. 2006;88(4):489-495.

15. Fukuda $\mathrm{H}$. The management of partial-thickness tears of the rotator cuff. J Bone Joint Surg Br. 2003;85(1):3-11.

16. Bey MJ, Ramsey ML, Soslowsky LJ. Intratendinous strain fields of the supraspinatus tendon: effect of a surgically created articular-surface rotator cuff tear. J Shoulder Elbow Surg 2002;11(6):562-569.

17. Reilly P. Amis AA, Wallace AL, Emery RJ. Supraspinatus tears: propagation and strain alteration. J Shoulder Elbow Surg. 2003;12(2):134-138

18. Sano H, Wakabayashi I, Itoi E. Stress distribution in the supraspinatus tendon with partial-thickness tears: an analysis using two-dimensional finite element model. J Shoulder Elbow Surg. 2006;15(1):100-105.
19. Smith MM, Sakuri G, Smith SM, et al. Modulation of aggrecan and ADAMTS expression in ovine tendinopathy induced by altered strain. Arthritis Rheum. 2008;58(4):1055-1066

20. Yang S, Park HS, Flores S, et al. Biomechanical analysis of bursal-sided partial thickness rotator cuff tears. J Shoulder Elbow Surg. 2009;18(3):379-385.

21. Chen Q. Two-dimensional finite element proof-of-concept modeling on rotator cuff tear scaffold efficacy. Technical Report from the Material and Structural Testing Core, Mayo Clinic, Rochester, Minnesota. 2011.

22. Van Kampen $C$, Arnoczky $S$, Parks $P$, et al. Tissue-engineered augmentation of a rotator cuff tendon using a reconstituted collagen scaffold: a histological evaluation in sheep. Muscles Ligaments Tendons J. 2013;3(3):229-235.

23. Bokor DJ, Sonnabend D, Deady L, et al. Preliminary investigation of a biological augmentation of rotator cuff repairs using a collagen implant: a 2 year MRI follow-up. Muscles Ligaments Tendons J. 2015;5(3):144-150.

24. Padulo J, Oliva F, Frizziero A, Maffulli N. Muscles, Ligaments, and Tendons Journal. Basic principles and recommendations in clinical and field science research. 2014:3(4):250-252.

25. Codman EA. The Shoulder: Rupture of the supraspinatus tendon and other lesions in or about the subacromial bursa. Boston: Thomas Todd; 1934. Reprint Edition. Malabar, FL: Robert E. Kreiger. 1984

26. Budoff JE, Nirschl RP, Guidi EJ. Debridement of partial-thickness tears of the rotator cuff without acromioplasty. Long-term follow-up and review of the literature. J Bone Joint Surg Am. 1998;80(5):733-748.

27. Gartsman GM, Milne JC. Articular surface partial-thickness rotator cuff tears. J Shoulder Elbow Surg. 1995;4(6):409-415.

28. Weber SC. Arthroscopic debridement and acromioplasty versus mini-open repair in the treatment of significant partial-thickness rotator cuff tears. Arthroscopy. 1999;15(2): 126-131.

29. Evans ND, Oreffo RO, Healy E, Thurner PJ, Man YH. Epithelial mechanobiology, skin wound healing, and the stem cell niche. J Mech Behave Biomed Mater. 2013;28:397-409.

30. Steiner M, Claes L, Ignatius A, Simon U, Wehner T. Disadvantages of interfragmentary shear on fracture healing-mechanical insights through numerical simulation. J Orthop Res. 2014;32(7):865-872.

31. Kamps BS, Linder LH, DeCamp CE, Haut RC. The influence of immobilization versus exercise on scar formation in the rabbit patellar tendon after excision of the central third. Am J Sports Med. 1994;22(6):803-811.

32. Sonnabend DH, Yu Y, Howlett CR, Harper GD, Walsh WR Laminated tears of the human rotator cuff: a histologic and immunochemical study. J Shoulder Elbow Surg. 2001;10(2):109115.

33. Altchek DW, Warren RF, Wickiewicz TL, Skyhar MJ, Ortiz G, Schwartz E. Arthroscopic acromioplasty. Technique and results. J Bone Joint Surg Am. 1990;72(8):1198-1207.

34. Ryu RK. Arthroscopic subacromial decompression: a clinical review. Arthroscopy.1992;8(2):141-147.

35. Keener JD, Galatz LM, Teefey SA, et al. A prospective evaluation of survivorship of asymptomatic degenerative rotator cuff tears. J Bone Joint Surg Am.2015;97:89-98. 